\title{
New Spirorotenoids from Tephrosia candida
}

Cesar C. Andrei ${ }^{\mathrm{a}}$, Paulo C. Vieira ${ }^{\mathrm{b}, *}$, João B. Fernandes ${ }^{\mathrm{b}}$, M. Fátima das G. F. da Silva ${ }^{\mathrm{b}}$ and Edson Rodrigues Fo. ${ }^{\mathrm{b}}$

a Departamento de Química, Universidade Federal de Londrina, Londrina, PR, Brazil

b Departamento de Química, Universidade Federal de São Carlos, CP 676, 13565-905, São Carlos, SP, Brazil. E-mail: paulo@dq.ufscar.br

* Author for correspondence and reprint requests

Z. Naturforsch. 57 c, 418-422 (2002); received January 22/February 18, 2002

Tephrosia candida, Fabaceae, Spirorotenoids

The ethyl acetate extract of roots of Tephrosia candida afforded three new spirorotenoids belonging to a new class of spirocompounds, named tephrospirolactone, tephrospiroketone I, and tephrospiroketone II. The structures of these compounds were determined mainly based on spectral analysis. The only known spirorotenoid described in the literature is amorphispironone, isolated from Amorpha fruticosa.

\section{Introduction}

The genus Tephrosia belongs to the family Fabaceae, which is well-known to be a rich source of flavonoids, besides the rotenoids among their secondary metabolites. Rotenoids, an interesting class of compounds showing mainly activity against insects, have also shown powerful ictiotoxic activity, fish poison. Rotenone was the first rotenoid identified and had been used as insecticide before the advent of the organosynthetic insecticides (Jacobson, 1971). Recently, properties as anticarcinogenic activities have also been attributed to rotenoids. Tephrosin and amorphispironone (1) isolated from Amorpha species have shown a potential use against tumours including skin cancer (Konoshima et al., 1993 and Li et al., 1993).

We have been interested in the chemistry of T. candida and have described the isolation of rotenoids from this plant (Andrei et al., 1997 and Pereira et al.,1998). In continuation of the study of the roots of $T$. candida we now describe the isolation and identification of three spirorotenoids, which represent a new spiroclass system formed by the rings $\mathrm{B}$ and $\mathrm{C}$, a different spiro system type of amorphispironone, the only known spirorotenoid (Li et al.,1991).

\section{Materials and Methods}

\section{General experimental procedures}

A Bruker DRX-400 spectrometer, operating at $400.13 \mathrm{MHz}$ for ${ }^{1} \mathrm{H}$ and $100.62 \mathrm{MHz}$ for ${ }^{13} \mathrm{C}$ NMR was used. All spectra were run in $\mathrm{CDCl}_{3}$ and with TMS as internal standard. Optical rotations were measured with a Perkin-Elmer polarimeter. Mass spectra were obtained with a HP 5987A spectrometer.

\section{Plant material}

Roots of T. candida (Roxb.) DC were collected and identified in the Instituto Agronômico do Paraná, PR, Brazil, January 1988. Voucher specimens are deposited at the Herbário of Instituto Agronômico, Londrina, PR, Brazil.

\section{Extraction and isolation of compounds}

The roots were dried in an open stove at $60{ }^{\circ} \mathrm{C}$ and powdered affording $2.7 \mathrm{~kg}$. Exhaustive extraction with ethyl acetate after hexane extraction, gave $36.5 \mathrm{~g}$ of crude extract (dry weight). A part of the ethyl acetate extract $(8.0 \mathrm{~g})$ was submitted to droplet countercurrent chromatography (DCCC) using an ascending system obtained from the mixture of the following solvents hexane: $\mathrm{CHCl}_{3}: \mathrm{CH}_{3} \mathrm{CN}$ $(10: 3: 7 \mathrm{v} / \mathrm{v} / \mathrm{v})$. A fraction $(2275 \mathrm{mg})$ was submitted to column chromatography (70-230 mesh) eluted with hexane and ethyl acetate with increasing polarity. Purification of the fractions with silica gel columns (230-400 mesh), preparative tlc on silica eluted with hexane: $\mathrm{CH}_{2} \mathrm{Cl}_{2}: \mathrm{MeOH}(50: 49: 1 \mathrm{v} / \mathrm{v} / \mathrm{v})$ and recycling preparative $\mathrm{HPLC}$ on silica gel using as eluent a mixture hexane: $\mathrm{CH}_{2} \mathrm{Cl}_{2}: i-\mathrm{PrOH}$ $(80: 10: 1 \mathrm{v} / \mathrm{v} / \mathrm{v})$ afforded tephrospirolactone (2) 
(7.3 mg), tephrospiroketone $I$ (3) (5.2 $\mathrm{mg})$ and tephrospiroketone $I I$ (4) (1.2 $\mathrm{mg})$.

Tephrospirolactone $(2):[\alpha]_{\mathrm{D}}^{25}+9.5^{\circ}(4.5 \mathrm{mg} / \mathrm{ml}-$ $\mathrm{CH}_{2} \mathrm{Cl}_{2}$ ). IR $v_{\max } \mathrm{KBr} \mathrm{cm}^{-1}: 1748,1681,1611$, and 1583. EIMS $m / z$ (rel. int.): 424(4), 222(3), 203(30), 202(27), 187(100) and 180(14). ${ }^{1} \mathrm{HNMR}\left(\mathrm{CDCl}_{3}\right.$, $400 \mathrm{MHz})$ : Table I. ${ }^{13} \mathrm{CNMR}\left(\mathrm{CDCl}_{3}, 100 \mathrm{MHz}\right)$ : Table II. HMBC $\left(\mathrm{CDCl}_{3}, 100 / 400 \mathrm{MHz}\right)$ : Table III.

Thephrospiroketone $I(3):[\alpha]_{\mathrm{D}}^{25}+30.9^{\circ}(4.2 \mathrm{mg} /$ $\mathrm{ml}-\mathrm{CH}_{2} \mathrm{Cl}_{2}$ ). IR $v_{\max } \mathrm{KBr}, \mathrm{cm}^{-1}: 1716,1675$, 1607, and 1507. EIMS: $m / z$ (rel. int.): 408(32), 393(17), 213(26) and 180(100). ${ }^{1} \mathrm{H}$ NMR $\left(\mathrm{CDCl}_{3}\right.$, $400 \mathrm{MHz})$ : Table I. ${ }^{13} \mathrm{C} \mathrm{NMR}\left(\mathrm{CDCl}_{3}, 100 \mathrm{MHz}\right)$ : Table II.

Tephrospiroketone $I I$ (4): ${ }^{1} \mathrm{H}$ NMR $\left(\mathrm{CDCl}_{3}, 400\right.$ $\mathrm{MHz})$ : Table I. ${ }^{13} \mathrm{C}$ NMR $\left(\mathrm{CDCl}_{3}, 100 \mathrm{MHz}\right)$ : Table II.

\section{Results and Discussion}

The infrared spectra showed absorption of carbonyls at 1681,1748 and $1675 \mathrm{~cm}^{-1}$, and $1716 \mathrm{~cm}^{-1}$ for 2 and 3 respectively. The absorption $1748 \mathrm{~cm}^{-1}$ was attributed to a carbonyl of an $\alpha, \beta$-dihydro- $\delta$ lactone ring and the one $1716 \mathrm{~cm}^{-1}$ to the $\alpha, \beta$ dehydro-cyclopentanone, while absorptions close to $1680 \mathrm{~cm}^{-1}$, are usually observed for carbonyls of 6 a, 12a-dihydrorotenoids

The ${ }^{1} \mathrm{H}$ NMR of the three compounds displayed an AB coupling system for two geminal hydrogens, neighbouring the quaternary carbon of the spirorings (Table I). This system has never been observed before for any rotenoids. Other signals showed to be characteristic of hydrogens in the rings $\mathrm{A}, \mathrm{D}$ and $\mathrm{E}$, exhibiting differences of the chemical shifts, in comparison with deguelin (5) (Andrei et al. 1997) and rotenone (6) (Birch et al. 1985) as models. The chemical shifts observed for H-1 and H-4 in the ring A (Table I) exhibited accentuated differences indicating the presence of an electron withdrawing substituent at the aromatic system. The hydrogens in the $\mathrm{D}$ and $\mathrm{E}$ rings showed closer chemical shifts when compared with those of the above deguelin and rotenone. The pair of doublets attributed to H-6 in the spirocompounds showed similar chemical shifts with those of the homoisoflavanone scillascillin (7). The diastereotopic protons of this compound (H-2) appear as an AB system, displayed at $\delta 4.52$ and 4.62 $(J=11.0 \mathrm{~Hz})$ (Heller and Tamm, 1981).

The ${ }^{13} \mathrm{C}$ NMR chemical shifts were attributed to the carbons of compounds $\mathbf{1}, \mathbf{2}$ and $\mathbf{3}$, having rotenone (6) (Crombie et al., 1975) and deguelin (5) (Andrei et al.,1997) as models (Table II). The chemical shifts of C-6a and the additional carbonyl in $\mathrm{C}-12 \mathrm{a}$ of the new compounds have never been described for common rotenoid skeleta before. The data of Table II are in agreement with the proposed structures.

When compared with the model compounds the main differences observed were: deshielding of C-3 and C-4a $(\Delta \delta \sim 8 \mathrm{ppm})$, suggesting the addi-

Table I. ${ }^{1} \mathrm{H}$ NMR data for spirocompounds $\left(\mathrm{CDCl}_{3}, 400 \mathrm{MHz}\right)$. Rotenone (Birch et al., 1985) and deguelin (Andrei et al.,1997) were used as models.

\begin{tabular}{llllll}
\hline $\mathrm{H}$ & $\begin{array}{l}\text { Tephrospiro- } \\
\text { lactone (2) }\end{array}$ & Deguelin (5) & $\begin{array}{l}\text { Tephrospiro- } \\
\text { ketone I (3) }\end{array}$ & $\begin{array}{l}\text { Tephrospiro- } \\
\text { ketone II (4) }\end{array}$ & Rotenone (5) \\
\hline 1 & $7.18 s$ & $6.72 s$ & $7.27 s$ & $7.27 s$ & $6.77 s$ \\
4 & $6.51 s$ & $6.38 s$ & $6.53 s$ & $6.53 s$ & $6.46 s$ \\
$6 \alpha$ & $4.54 d(12)$ & $4.11 d(12.4)$ & $4.63 d(12.4)$ & $4.63 d(12.4)$ & $4.19 d(12)$ \\
$6 \beta$ & $4.78 d(12)$ & $4.56 d d(12.4,3.2)$ & $4.69 d(12.4)$ & $4.70 d(12.4)$ & $4.62 d d(12,3)$ \\
10 & $6.53 d(8.8)$ & $6.38 d(8.8)$ & $6.57 d(8.8)$ & $6.65 d(8.8)$ & $6.52 d(8.6)$ \\
11 & $7.74 d(8.8)$ & $7.67 d(8.8)$ & $7.44 d(8.8)$ & $7.56 d(8.8)$ & $7.84 d(8.6)$ \\
$4^{\prime}$ & $6.36 d(10)$ & $6.57 d(10)$ & $6.55 d(10)$ & $3.03 / 3.43 d d$ & $2.95 / 3.33 d d$ \\
& & & & $(15.6,8.0 / 12.8,9.6)$ & $(15.8,8.0 / 15.8,9.8)$ \\
$5^{\prime}$ & $5.55 d(10)$ & $5.48 d(10)$ & $5.62 d(10)$ & $5.38 t(8.0)$ & $5.25 t(8.8)$ \\
$7^{\prime}$ & $1.41 s$ & $1.32 s$ & $1.49 s$ & $4.98 / 5.11 b s$ & $4.94 / 5.08 s$ \\
$8^{\prime}$ & $1.43 s$ & $1.38 s$ & $1.52 s$ & $1.79 s$ & $1.77 s$ \\
OMe (2) & $3.85 s$ & $3.70 s$ & $3.88 s$ & $3.88 s$ & $3.77 s$ \\
OMe (3) & $3.96 s$ & $3.73 s$ & $3.96 s$ & $3.96 s$ & $3.81 s$ \\
\hline
\end{tabular}

Coupling constants $(\mathrm{Hz})$ in parentheses. 


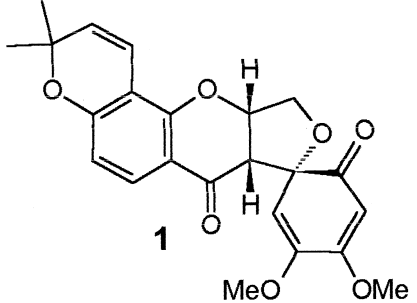<smiles>COc1cc2c(cc1OC)C(=O)[C@@]1(CO2)Oc2c(ccc3c2C=CC(C)(C)O3)C1=O</smiles><smiles>COc1cc2c(cc1OC)[C@@H]1C(=O)c3ccc4c(c3O[C@H]1CO2)C=CC(C)(C)O4</smiles><smiles>COc1cc2c(cc1OC)C(=O)C1(CO2)OC(=O)c2ccc3c(c2O1)C=CC(C)(C)O3</smiles><smiles>C=C(C)C1Cc2c(ccc3c2OC2(COc4cc(OC)c(OC)cc4C2=O)C3=O)O1</smiles><smiles>C=C(C)C1Cc2c(ccc3c2O[C@H]2COc4cc(OC)c(OC)cc4[C@H]2C3=O)O1</smiles><smiles>O=C1c2c(O)cc(O)cc2OCC12Cc1cc3c(cc12)OCO3</smiles>

Fig. 1. Structures of rotenoids amorphispironone (1), tephrospirolactone (2), tephrospiroketone $I(\mathbf{3})$, tephrospiroketone $I I(\mathbf{4})$, deguelin (5), rotenone (6) and scillascillin (7).

tional withdrawing effect of the conjugated carbonyl at $\mathrm{C}-12 \mathrm{a}$; C-6 is deshielded $(\Delta \delta \sim 5 \mathrm{ppm})$ due to $\beta$-effect of the quaternary carbon (6a); $\mathrm{C}-7 \mathrm{a}$ of the spiroketones showed deshielding of $9 \mathrm{ppm}$ due to their presence in a five membered ring; the spirolactone with a six member ring showed a shielding for $\mathrm{C}-11 \mathrm{a}(\Delta \delta=6.1 \mathrm{ppm})$ that can be explained by the electron donor effect of the lactone oxygen to $\mathrm{C}-12$ and the chemical shifts for C-7a , C-8, C-9 and C-10 of spiroketones are deshielded in comparison with the models, while $\mathrm{C}-11$ are shielded of $4 \mathrm{ppm}$ in both cases.
The HMBC spectrum of tephrospirolactone (2)(Table III) showed cross peaks between hydrogens and carbons $\left({ }^{2} J\right.$ and $\left.{ }^{3} J\right)$ that confirmed the proposed structure. The main correlation was observed between C-6a and the diasterotopic hydrogens at C-6.

EI/MS also corroborated the structures proposed for the spirocompounds. The spectrum showed two possibilities of a retro Diels-Alder rearrangement. The base peak for $\mathbf{2}$, could be explained by a retro Diels-Alder between C and D rings, followed by a common loss of a methyl 
Table II. ${ }^{13} \mathrm{C}$ NMR data* for spirorotenoids $\left(\mathrm{CDCl}_{3}, 100 \mathrm{MHz}\right)$. Rotenone (Crombie et al., 1975) and deguelin (Andrei et al., 1997) were used as models.

\begin{tabular}{|c|c|c|c|c|c|}
\hline $\mathrm{C}$ & $\begin{array}{l}\text { Tephrospiro- } \\
\text { lactone (2) }\end{array}$ & Deguelin (5) & $\begin{array}{l}\text { Tephrospiro- } \\
\text { ketone I (3) }\end{array}$ & $\begin{array}{l}\text { Tephrospiro- } \\
\text { ketone II (4) }\end{array}$ & Rotenone (6) \\
\hline $\mathbf{1}^{\mathrm{a}}$ & 109.8 & 105.3 & 106.4 & 107.0 & 104.7 \\
\hline 1 & 107.1 & 110.7 & 106.9 & 106.6 & 110.4 \\
\hline 2 & 145.5 & 144.1 & 145.2 & 145.3 & 143.9 \\
\hline 3 & $157.4^{\dagger}$ & 149.8 & 157.2 & 157.3 & 149.5 \\
\hline 4 & 100,0 & 101.2 & 100.1 & 100.2 & 100.9 \\
\hline $4^{a}$ & $157.7^{\dagger}$ & 147.7 & 158.2 & 158.3 & 147.4 \\
\hline 6 & 71.7 & 66.5 & 71.0 & 71.0 & 66.3 \\
\hline $6^{a}$ & 95.6 & 72.7 & 86.7 & 86.7 & 72.2 \\
\hline $7^{\mathrm{a}}$ & 150.5 & 150.0 & 161.8 & $168.8^{\dagger}$ & 156.1 \\
\hline 8 & 108.8 & 109.4 & $112.2^{\ddagger}$ & $113.1^{*}$ & 113.0 \\
\hline 9 & $159.3^{\ddagger}$ & 160.3 & 169.0 & $169.7^{\dagger}$ & 167.4 \\
\hline 10 & 112.3 & 111.7 & 113.3 & 109.5 & 104,7 \\
\hline 11 & 130.0 & 128.9 & 125.1 & 126.5 & 130.0 \\
\hline $11^{\mathrm{a}}$ & 106.9 & 113.0 & $113.2^{\ddagger}$ & $114.2^{\ddagger}$ & 114.7 \\
\hline 12 & $159.6^{*}$ & 189.4 & 182.9 & 183.0 & 188.9 \\
\hline $12^{\mathrm{a}}$ & 181.3 & 44.6 & 193.0 & 192.7 & 44,6 \\
\hline $4^{\prime}$ & 114.5 & 116.0 & 114.4 & 31.5 & 31.3 \\
\hline $5^{\prime}$ & 130.0 & 128.9 & 129.2 & 88.3 & 87.8 \\
\hline $6^{\prime}$ & 77.9 & 77.9 & 78.3 & 142.6 & 143.0 \\
\hline $7^{\prime} / 8^{\prime}$ & $28.2 / 28.5$ & $28.4 / 28.7$ & $28.4 / 28.5$ & 112.2/17.1 & 112.6/17.2 \\
\hline $\mathrm{OMe}(2)$ & 56.2 & 56.1 & 56.2 & 56.3 & 55.8 \\
\hline $\mathrm{OMe}(3)$ & 56.5 & 56.7 & 56.4 & 56.5 & 56.3 \\
\hline
\end{tabular}

* Multiplicity obtained by PENDANT.

$\dagger$ and $\ddagger-\delta$ values interchangeable in each column.

Table III. Correlation observed in the HMBC spectrum for tephrospirolactone (2) $\left(\mathrm{CDCl}_{3}, 100 / 400 \mathrm{MHz}\right)$.

\begin{tabular}{lcc}
\hline $\mathrm{H} / \mathrm{C}$ & ${ }^{2} J$ & ${ }^{3} J$ \\
\hline $6 \alpha$ & $6 \mathrm{a}$ & $4^{\mathrm{a}}$ \\
$6 \beta$ & $6 \mathrm{a}$ & $4 \mathrm{a}$ and $12 \mathrm{a}$ \\
11 & - & $7 \mathrm{a}, 9$ and 12 \\
4 & 3 and $4 \mathrm{a}$ & $1 \mathrm{a}$ and 2 \\
1 & -- & 3 and $4 \mathrm{a}$ \\
$4^{\prime}$ & -- & 9 and $6^{\prime}$ \\
$5^{\prime}$ & $6^{\prime}$ & 8 \\
Me $\left(7^{\prime} / 8^{\prime}\right)$ & $6^{\prime}$ & $5^{\prime}$ \\
OMe (2) & - & 2 \\
OMe (3) & - & 3 \\
\hline
\end{tabular}

group of the chromene ring. Mass spectrum of $\mathbf{3}$, also presented the base peak due to the only one retro Diels-Alder type fragmentation.

Rotenoid biosynthesis is already well-known (Crombie, 1984 and Crombie and Whitting, 1998). These two last reviews show the main biosynthetic pathways. The biosynthetic pathway for amorphispironone 1, isolated from Amorpha fruticosa (Li et al., 1991; Terada et al.,1993) was discussed by Li (1991), and also mentioned by Crombie (1998). For the spiroketones $\mathbf{3}$ and $\mathbf{4}$, a similar first step mechanism with an epoxidation, like in amorphispironone, can be suggested. Therefore, the starting compound should be the 6a,12a-dehydrodeguelin. The epoxidation should occur between C-6a and C-12a. In a hydrate form at C-12 carbonyl, a pinacol-pinacolone type rearrangement could lead to the spiro compounds, after interconversion to the carbonylated form and oxidation of $\mathrm{C}-12 \mathrm{a}$ into a keto group. Subsequent oxidation by a Baeyer-Villiger reaction type at C-12 and expansion to a six membered lactone ring could explain the formation of the spirolactone $\mathbf{2}$.

\section{Acknowledgements}

The authors are grateful to FAPESP, CNPq, FINEP and CAPES for the financial support, to Alberto S. Pereira and Dr. Angelo Cunha Pinto (Instituto de Química, Universidade Federal do Rio de Janeiro, Rio de Janeiro), for the mass spectra of tephrospirolactone. We also thank Dr. Sueli de Carvalho, Instituto Agronômico do Paraná de Londrina - PR - Brazil, for collecting and identifying Tephrosia candida. C. C. A. thanks CAPES/PICDT for the award of a scholarship. 
Andrei C. C., Vieira P. C., Fernandes J. B., da Silva M. F. G. F. and Rodrigues Fo. E. (1997), Dimethylchromene rotenoids from Tephrosia candida. Phytochemistry 46, 1081-1085.

Birch N., Crombie L. and Crombie M. W. (1985), Rotenoids of Lonchocarpus salvadorensis: Their effectiveness in protecting seeds against bruchid predation. Phytochemistry 24, 2881-2883.

Crombie L. (1984), Rotenoids and their biosynthesis. Nat. Prod. Rep. 1, 3-19.

Crombie L. and Whitting D. A. (1998), Biosynthesis in the rotenoid group of natural products: Applications of isotope methodology. Phytochemistry 49, 14791507.

Crombie L., Kilbee W. and Whiting D. A. (1975), Carbon-13 magnetic resonance spectra of natural rotenoids and their relatives. J. Chem. Soc. Perkin Trans. I, 1497-1499.

Heller W. and Tamm C. (1981), Homoisoflavanones and biogenetically related compounds. Progress in chemistry of organic natural products. New York. Springer 40, $117-120$.

Jacobson M. and Crosby D. G. (1971), Naturally Occurring Insecticides. Marcel Dekker, New York, pp. 71-73.

Konoshima T., Terada H., Kokumai M., Kozuka M., Tokuda H., Estes J. R., Li L., Wang H. and Lee K.
(1993), Studies on inhibitors of skin tumour promotion, XIL. Rotenoids from Amorpha fruticosa. J. Nat. Prod. 56, 843-848.

Li L., Wang H., Chang J., Mcphail A. T., Mcphail D. R. H., Konoshima T., Kokumai M., Kozuca M., Estes J. R. and Lee K. H. (1993), Antitumour agents, 138. Rotenoids and isoflavones as cytotoxic constituents from Amorpha fruticosa. J. Nat. Prod. 56, 690-698.

Li L. P., Wang H. K., Fujioka T., Chang J. J., Kozuka M., Konoshima T., Estes J. R., Mcphail D. R., Mcphail A. T. and Lee K. H. (1991), Structure and stereochemistry of amorphispironone, a novel cytotoxic spirone type rotenoid from Amorpha fruticosa. J. Chem. Soc. Chem. Commun. 1652-1653.

Pereira A. S., Pinto A. C., Cardoso J. N., Aquino Neto R., Vieira P. C., Fernandes J. B., da Silva M. F. G. F. and Andrei C. C. (1998), Analysis of rotenoids by high resolution gas chromatography-mass spectrometry. J. High Resol. Chromat. 21, 513-518.

Terada H., Kokumai M., Konoshima T., Kozuka M., Haruna M., Kazuo I., Estes J. R., Li L. P., Wang H. K. and Lee K. H. (1993), Structural elucidation and chemical conversion of amorphispironone, a novel spirone from Amorpha fruticosa, to rotenoids. Chem. Pharm. Bull. 41, 187-190. 